\title{
Pharmacologically Relevant Drug Interactions of Pramlintide (Amylin Analogue)
}

\author{
Naina Mohamed Pakkir Maideen* \\ Pharmacologist, Dubai Health Authority, UAE
}

*Corresponding author: Naina Mohamed Pakkir Maideen, Pharmacologist, Dubai Health Authority, PB No: 4545, Dubai, UAE

ARTICLE INFO

Received: 幽 February 25, 2019

Published: 蔧 March 08, 2019

Citation: Naina Mohamed Pakkir Maideen. Pharmacologically Relevant Drug Interactions of Pramlintide (Amylin Analogue). Biomed J Sci \& Tech Res 15(4)-2019. BJSTR. MS.ID.002739.

\begin{abstract}
Pramlintide is an Amylin analogue useful in the treatment of type 1 and type 2 diabetes mellitus. Pramlintide may delay the absorption of certain medications such as Acetaminophen (Paracetamol), by slowing down the gastric emptying. The absorption of Oral contraceptives and Antibiotics might also be delayed by the concurrent use of Pramlintide. Such interaction could be prevented by using them 1 hour before or 2 hours after Pramlintide administration.
\end{abstract}

Keywords: Drug Interactions; Amylin Analogue; Pramlintide; Type 1 Diabetes; Type 2 Diabetes.

\section{Introduction}

Pramlintide is an Amylin analogue and it helps to manage the blood glucose of patients with type 1 and type 2 diabetes mellitus [1]. The postprandial glucose concentrations are reduced by the administration of Pramlintide through at least three mechanisms including reduction of postprandial glucagon secretion, slowing of gastric emptying and suppression of appetite by a central mechanism. The reduction of postprandial glucagon secretion results in decreased glucose production from liver and the food intake is decreased by slowing of gastric emptying and the suppression of appetite [2]. Diabetes is one of the leading causes of cardiovascular diseases, blindness, kidney failure, amputations, and others. According to International Diabetes Federation (IDF), globally 451 million were affected by Diabetes, in 2017 and it has been projected that the global population with diabetes would reach around 693 million by 2045 . It has also been estimated that approximately 5 million global deaths and 850 billion US dollars of healthcare costs were attributed to diabetes in the year of 2017 [3].

Polypharmacy is very common among the patients with diabetes and the incidence of drug interaction is higher in patients with diabetes as they may take several medications to treat comorbid conditions such as cardiovascular diseases, hepatic diseases, renal problems, depression, and others along with the medications controlling blood glucose [4]. Interference of effects of one drug by other drug(s), supplements, food, smoking or alcohol consumption, is known as Drug interaction [5]. In addition, the drug interaction resulting in elevated risk of adverse effects or decreased therapeutic efficacy is termed Adverse Drug Interaction $[6,7]$. Pramlintide may slow down the absorption of certain orally administered drugs as it delays the gastric emptying.

\section{Acetaminophen (Paracetamol)}

Acetaminophen is an antipyretic drug and millions daily, worldwide, use it. It is frequently employed as a marker of gastric emptying due to its high permeability and high solubility [8]. Concomitant use of Pramlintide and Acetaminophen resulted in slowed absorption of acetaminophen. However, this interaction is clinically insignificant [9]. The patients may take Acetaminophen or other analgesics 1 hour before or 2 hours after Pramlintide administration for better analgesia.

\section{Oral Contraceptives}

Rapid absorption of oral contraceptives is essential to prevent the unwanted pregnancy and Pramlintide may slow down the absorption of oral contraceptives due to delayed gastric emptying [10]. The patients on Pramlintide may take Oral contraceptives 1 hour before or 2 hours after the administration of Pramlintide [11].

\section{Antibiotics}

The gastric uptake of Antibiotics might be interfered by the concomitant administration of Pramlintide which may affect 
therapeutic efficacy of Antibiotics [10]. If concurrent use of Pramlintide and Antibiotics is necessary, Antibiotics might be administered 1 hour before or 2 hours after the administration of Pramlintide.

\section{a-glucosidase Inhibitors}

The $\alpha$-Glucosidase inhibitors are oral antidiabetic medications used to treat patients with type 2 diabetes and they include Acarbose, Miglitol and Voglibose. They slow down the intestinal absorption of nutrients by increasing the gastrointestinal motility and the coadministration of Pramlintide with $\alpha$-Glucosidase inhibitors may interfere further with their absorption [12].

\section{Insulins}

Mixing of Pramlintide with Insulins in a single syringe may affect the compatibility of either drugs due to $\mathrm{pH}$ differences. The manufacturer advises to avoid mixing of Pramlintide and Insulins in the same syringe to prevent this pharmaceutical interaction [13].

\section{Conclusion}

No clinically significant drug interactions have been reported with the use of Pramlintide, though there are few possible interactions related to delayed absorption of oral medications. Pramlintide slowed down the absorption of Acetaminophen (Paracetamol) by delaying the gastric emptying and it may also delay the absorption of Oral contraceptives and Antibiotics through similar mechanism. The intestinal absorption of nutrients might be interfered by the concomitant use of Pramlintide and $\alpha$-Glucosidase inhibitors such as Acarbose, Miglitol and Voglibose. The compatibility of Insulin or Pramlintide could be affected by mixing them in a same syringe. Future studies are needed to confirm the interaction of Pramlintide with Anticholinergics and the drugs having anticholinergic potential such as Antihistamines, Antidepressants and others.

\section{References}

1. Ryan GJ, Jobe LJ, Martin R (2005) Pramlintide in the treatment of type 1 and type 2 diabetes mellitus. Clinical therapeutics 27(10): 1500-1512.

\section{ISSN: 2574-1241}

DOI: 10.26717/BJSTR.2019.15.002739

Naina Mohamed Pakkir Maideen. Biomed J Sci \& Tech Res

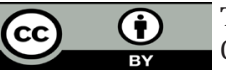

This work is licensed under Creative Commons Attribution 4.0 License

Submission Link: https://biomedres.us/submit-manuscript.php
2. Alrefai HA, Latif KA, Hieronymus LB, Weakley CR, Moss RJ (2010) Pramlintide: clinical strategies for success. Diabetes Spectrum 23(2): 124-130.

3. Cho NH, Shaw JE, Karuranga S, Huang Y, da Rocha Fernandes JD, et al. (2018) IDF Diabetes Atlas: Global estimates of diabetes prevalence for 2017 and projections for 2045. Diabetes research and clinical practice 138: $271-281$.

4. Ibrahim IA, Kang E, Dansky KH (2005) Polypharmacy and possible drugdrug interactions among diabetic patients receiving home health care services. Home health care services quarterly 24(1-2): 87-99.

5. Pakkir Maideen NM, Manavalan G, Balasubramanian K (2010) Drug interactions of meglitinide antidiabetics involving CYP enzymes and OATP1B1 transporter. Therapeutic advances in endocrinology and metabolism 9(8): 259-268.

6. Maideen NM (2019) Tobacco smoking and its drug interactions with comedications involving CYP and UGT enzymes and nicotine. World Journal of Pharmacology 8(2): 14-25.

7. Maideen NM, Balasubramaniam R (2018) Pharmacologically relevant drug interactions of sulfonylurea antidiabetics with common herbs. Journal of Herbmed Pharmacology 7(3): 200-210.

8. Ayalasomayajula S, Meyers D, Koo P, Salunke A, Majumdar T, et al. (2015) Assessment of pharmacokinetic drug-drug interaction between pradigastat and acetaminophen in healthy subjects. European journal of clinical pharmacology 71(4): 425-432.

9. Kellmeyer TA, Kesty NC, Wang Y, Frias JP, Fineman MS (2007) Pharmacokinetics of an oral drug (acetaminophen) administered at various times relative to subcutaneous injection of pramlintide in subjects with type 2 diabetes. The Journal of Clinical Pharmacology 47(7): 798-805.

10. Childs BP (2006) Pramlintide use in type 1 diabetes resulting in less hypoglycemia. Diabetes Spectrum 19(1): 50-52.

11. Carpio GR, Fonseca VA (2014) Update on safety issues related to antihyperglycemic therapy. Diabetes Spectrum 27(2): 92-100.

12. Younk LM, Mikeladze M, Davis SN (2011) Pramlintide and the treatment of diabetes: a review of the data since its introduction. Expert opinion on pharmacotherapy 12(9): 1439-1451.

13. Weyer C, Fineman MS, Strobel S, Shen L, Data J, et al. (2005) Properties of pramlintide and insulin upon mixing. American journal of health-system pharmacy 62(8): 816-822.

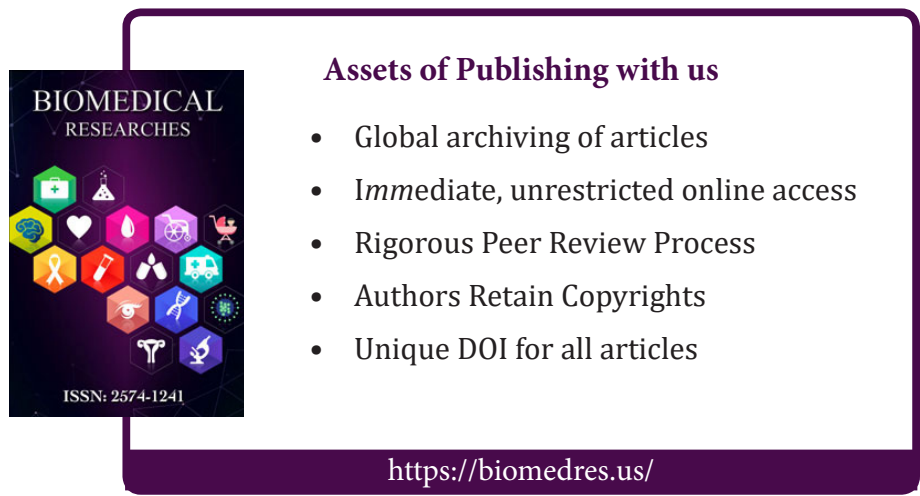

Copyright@ Naina Mohamed Pakkir Maideen | Biomed J Sci \& Tech Res| BJSTR. MS.ID.002739. 